\title{
A CASE OF CAVITARY DISEASE, LUNG, ETIOLOGY UNDETERMINED, COMPLICATED BY ASPERGILLUS
}

\author{
MAKOTO TANABE \\ Department of Internal Medicine, School of Medicine, Keio University
}

(Received for publication, October 7, 1960)

INTRODUCTION

Recently fungus diseases have been discussed in Japan. In U.S.A. there is a fairly high percentage of fungus disease. Aspergillus fumigatus is the species most frequently associated with disease. The most common form of this disease is a chronic granulomatous infection in which the symptoms resemble tuberculosis. Also a chronic active form of pulmonary Histoplasmosis exists that closely resembles pulmonary tuberculosis. In Dunham Hospital, Cincinnati, Ohio there was a case of pulmonary Histoplasmosis which was treated medically with Amphotericin B and later the left upper lobe was successfully removed. But numerous attempts to demonstrate fungus elements in the pulmonary tissue were negative and they found fungus ball caused by Aspergillus fumigatus demonstrated by culture. The following is a report on this case.

\section{PRESENTATION OF CASE}

A 47 year old minister, was admitted to a Dunham Hospital, Cincinnati, Ohio on August, 9, 1959, because of severe intermittent hemoptisis for 5 days. Since his last admission to the Jewish Hospital, Cincinnati, Ohio he had been doing fairly well until April, 1959 when he began to lose weight (15lbs.), and to cough and to produce sputum. In the past he had been admitted several times to the Jewish Hospital. The first admission was on August 22, 1955 and diagnosed as Laennec's cirrhosis; chronic cholecystitis; question of duodenal ulcer. At this time the chest X-ray revealed fibroid infiltrate in left apex. Second admission was on September 23, 1955 and diagnosed as acute hepatic exacerbation with impending coma. He was treated with meticorten, $10 \mathrm{mg}$ every $8 \mathrm{hrs}$. In April 1956 he had bronchopneumonia at home and responded to antibiotics, but developed pleural effusion. Therefore he was admitted to the Jewish Hospital. At this time he had positive PPD and histoplasmin test. Had $50 \mathrm{cc}$ of fluid removed from chest which was negative for AFB on study. Fourth admission to Jewish Hospital was on April 21, 1957 for liver biopsy. Family history was not contributed. 
Physical examination on admission revealed an acutely ill man who was extremely uncomfortable because of expectorating about $200 \mathrm{cc}$ of blood daily. Temp. 101, Pulse 120, Respiration 30, BP 120/70. Skin revealed spider angiomata over the face and also palm erythema was noted. The lung showed dullness at both lung apices and rales. The liver was palpable 2 fingers below right constal margine on mid-clavicularline. The remainder of the examination was unremarkable.

Examination of the blood showed a hemoglobin of $9.4 \mathrm{~g}$ per $100 \mathrm{ml}$ and a Red cell count of 2,380,000. Examination of the urine was normal. BSP test revealed $13.8 \%$ of retention. Sputum on repeated examinations showed no AFB on concentrate. Cest X-ray showed moderate amount of fluffy infiltrate in the right upper lobe, and a heavy infiltrate with thickened pleura and an elongated cavity in the left upper lobe. Skin tests were positive for tuberculin and histoplasmin.

Blood spitting continued at a brisk rate and then gradually stopped over a period of 2 months. Results of several sputum cultures (6) were negative for Acid fast bacilli. Sputum cultures sent to Dr. Furcolow, Kansas City, Kansas, were negative for Histoplasma capsulatum and subcultures of their organs were also negative. Complement fixation tests are reported in a separate table. Diagnosis of histoplasmosis was made on the basis of results of complement fixation tests, positive skin test and absence of proof of tuberculosis.

Non-specific treatment with chloromycetin and penicillin was given with no clinical improvement or X-ray change from the time of admission to September 19, 1959. Treatment of histoplasmosis with Amphotericin B was started on September 19, 1959. The initial dose was one fourth $\mathrm{mg} / \mathrm{kg}$ of body weight and this was gradually increased every other day to $65 \mathrm{mg}$ total. The treatment was continued 3 to 4 times per week, the medication being given in $1000 \mathrm{cc}$ of $5 \%$ glucose with sulfadiazine over a 6 -hour period. The patient sometimes experienced chills and fever with this and always lost his appetite on the days of the treatment. However he did gain weight from 114 to $125 \mathrm{lbs}$ and his $\mathrm{X}$-ray showed considerable improvement, especially on the right, but the cavity on the left persisted. Planiograms were taken of this cavity area to seek out the possible presence of a fungs ball, but there was no rim of air seen.

The treatment with Amphoteracin was discontinued on February 12 after 5 months of treatment in order to improve the nutritional status of the patient in preparation for a left upper lobectomy. He gained weight from 125 to 140 lbs and in addition his liver function studies improved.

Pulmonary function tests revealed vital capacity, $2.24 \mathrm{~L}(54.1 \%)$ and maxi- 
mum breathing capacity $101.0 \mathrm{~L}(89.0 \%)$, Bronchospirometry study showed vital capacity, right $60.8 \%$ and left $39.2 \%$, oxygen uptake, right $71.1 \%$ and left $28.9 \%$, minutes ventilation, right $70.7 \%$ and left $29.3 \%$. Pulmonary compliance showed $0.109 \mathrm{~L} / \mathrm{cm} \mathrm{H}_{2} \mathrm{O}$ on the right lung, $0.091 \mathrm{~L} / \mathrm{cm} \mathrm{H}_{2} \mathrm{O}$ on the left lung and $0.132 \mathrm{~L} / \mathrm{cm}$ $\mathrm{H}_{2} \mathrm{O}$ on both lungs. Total air flow resistance showed $8.984 \mathrm{~cm} \mathrm{H}_{2} \mathrm{O} / \mathrm{L} / \mathrm{sec}$ on the right, $16.734 \mathrm{~cm} \mathrm{H}_{2} \mathrm{O} / \mathrm{L} / \mathrm{sec}$ on the left and $2.491 \mathrm{~cm} \mathrm{H}_{2} \mathrm{O} / \mathrm{L} / \mathrm{sec}$ on both lungs. Inspiratory air flow resistance revealed $5.812 \mathrm{~cm} \mathrm{H}_{2} \mathrm{O} / \mathrm{L} / \mathrm{sec}$ on the right lung, $15.301 \mathrm{~cm} \mathrm{H} \mathrm{H}_{2} \mathrm{O} / \mathrm{L} / \mathrm{sec}$ on the left lung and $1.655 \mathrm{~cm} \mathrm{H}_{2} \mathrm{O} / \mathrm{L} / \mathrm{sec}$ on both lungs. Expiratory air flow resistance showed $10.788 \mathrm{~cm} \mathrm{H}_{2} \mathrm{O} / \mathrm{L} / \mathrm{sec}$ on the right lung, $17.534 \mathrm{~cm} \mathrm{H} \mathrm{H}_{2} \mathrm{O} / \mathrm{L} / \mathrm{sec}$ on the left lung and $3.020 \mathrm{~cm} \mathrm{H}_{2} \mathrm{O} / \mathrm{L} / \mathrm{sec}$ on both lungs. The separated values of compliance and air flow resistance of each lung were measured by using bronchospirometry.

On April 29, 1960 a left upper lobectomy was performed and followed by a "tailoring" thoracoplasty on May 17, 1960 because of incomplete expansion of the remaining lung. We again attempted giving Amphoteracin $B$ and he did receive four treatments preoperatively and five postoperatively, but these were accompanied by rather severe systemic reactions and so these were discontinued.

He is now in fair shape and is gradually gaining weight which he lost during the postoperative period. He has no cough or expectoration. The right lung has remained stable and the left lung showed no infiltration.

Surgical specimen consisted of the left upper lobe which showed considerable shrinkage and very severe thickening of the pleura, which in many parts was $4-5 \mathrm{~mm}$ in thickness and extraordinarily firm, obviously due to fibrosis and hyalinization. The lung was incised and an area of scarring and inflammation in the upper two thirds of the lobe. In the apex of the shrunken lobe, there was a cavity of $3 \times 3.5 \mathrm{~cm}$, the walls of which were covered by brownish masses typical for the presence of Aspergillus (fungus ball). The major part of this material had been removed and separately submitted and was brownish and approximately $2 \times 3 \mathrm{~cm}$ in diameter. The pulmonary tissue adjacent to the cavity was extraordinarily and grayish in color except for areas where bronchi were seen. These bronchi are markedly distended and very obviously the wall of the bronchi was massively infiltrated by inflammatory or organizing tissue and measures several $\mathrm{mm}$ as a rule. In some of the bronchi, even far distal from the cavity, the brownish content was found which almost certainly represented extention of Aspergillus into these bronchi. The pleural thickening over the cavity was enormous and felt almost stony but did not seem to contain, at least to gross inspection, calcium. In microscopic examination there was extraordinary degree of fibrosis in the wall and surrounding the wall of cavity. Numer- 
ous attempts to demonstrate fungus elements in the pulmonary tissue were negative. There were fungus ball caused by Aspergillus fumigatus which was demonstrated by culture, massive thickening of pleura, bronchiectasis and atelectasis and chronic interstitial pneumonitis. The pathological conclusion is cavitary disease, lung, etiology undetermined, complicated by aspergilloma.

\section{DISCUSSION}

Diagnois of this case was really difficult. This case was sent to Dunham Hospital as a diagnosis of pulmonary tuberculosis by a physician. Diagnosis of histoplasmosis was made by us on the basis of complement fixation tests, positive skin test and absence of proof of tuberculosis. However pathological report of surgical specimen revealed that they found fungus ball caused by Aspergillus fumigatus demonstrated by culture and that numerous attempts to demonstrate fungus elements in the pulmonary tissue were negative.

Chronic pulmonary histoplasmosis begins insidiously, or with symptoms of pharyngitis or pneumonia, usually with fever. The course is chronic, with chronic cough, mucopurulent sputum with occasional blood streak or small hemoptysis, weight loss, chest pain, weakness and fatigue as the principal symptoms. Roentgenographic examinations show that the lesions are nearly always in the apical portion of one or both lung fields. Marked fibrosis of the pulmonary lesions lead to displacement of the trachea and hilar structures toward the areas of maximal involvement. Cavities are frequently demostrable, often multiple and small in size; sometimes large and thin walled, resembling bullae. An unfavorable outcome is usually diminishing pulmonary function and intercurrent infections.

In chronic fibrocavitary pulmonary histoplasmosis, $H$. capsulatum is present in large numbers in the sputum and is readily isolated. The diagnosis of histoplasmosis has been made in some cases with persistently negative cultures because of characteristic lesions, positive skin test, positive serology, or both, in which tuberculosis was excluded and term "presumptive" was added to the diagnosis to distinguish such cases from those in which a definitive diagnosis was made by the demonstration of the etiologic agent.

Aspergillus is wide spread and abundant in nature, primary infection in man is rarely encountered. It is more commonly seen as a secondary infections disease in chronic pulmonary disorders, e.q., bronchogenic carcinoma, bronchiectasis, cysts and abscesses. The manifestation of this disease have been categorized into three groups: (1) the bronchitic with symptoms referable to those of an acute bronchitis; (2) the bronchopneumonic which is characterized 
by an abrupt onset of high fever, productive cough, dyspnea and progressive destruction of pulmonary tissue; and (3) the most common, a chronic granulomatous type, i.e., cough, night sweats, low grade evening fever, weight loss and scanty hemoptysis. There are no typical laboratory findings other than the presence of the fungus in the sputum but the organisms are frequent laboratory contaminants and even when they are repeatedly cultured from the sputum, their significance is in doubt. The white cell count is not appreciably altered although there may be an eosinophilia as high as 10 percent. The red cell count and hemoglobin are generally low due to the repeated bouts of hemoptysis and the chronicity of the disease.

The radiological picture of pulmonary aspergillosis varies greatly; however the most often reported finding is an increase in the size of the hilar shadows with weblike infiltrations radiating peripherally. A less often reported appearance is that resembling lobar pneumonia or bronchopnermonia. A rare radiological finding, reported to be pathognomonic is a solitary density with a clearly defined, thin, crescent-shaped area of radiolucency outlining the surperior limit of the mass which is usually located in the upper lobe areas.

This case fits chronic pulmonary histoplasmosis on symptoms, X-ray, serologic tests, skin tests. But we failed to demonstrate the organism in many sputum cultures as a definitive diagnosis. The improvement of X-ray findings after amphotericin B administration for histoplasmosis proved confusing because of specific treatment for histoplasmosis.

Serologic Tests for Histoplasmosis

\begin{tabular}{|c|c|c|c|c|c|c|c|}
\hline & \multicolumn{6}{|c|}{ Complement Fixation Test } & \multirow{3}{*}{$\frac{\text { Precipitin Test }}{\text { Kansas City }}$} \\
\hline & \multicolumn{2}{|c|}{ Kansas City } & \multicolumn{2}{|c|}{ Jewish Hospital } & \multicolumn{2}{|c|}{ Ohio State } & \\
\hline & Histoplasmin & $\begin{array}{l}\text { Yeast } \\
\text { Phase }\end{array}$ & Histoplasmin & $\begin{array}{l}\text { Yeast } \\
\text { Phase }\end{array}$ & Histoplasmin & $\begin{array}{l}\text { Yeast } \\
\text { Phase }\end{array}$ & \\
\hline $9 / 3 / 59$ & $1-16$ & $1-64$ & $1-4$ & $1-64$ & $1-16$ & $1-32$ & \\
\hline $9 / 29 / 59$ & 0 & $1-128$ & & & & & \\
\hline $10 / 27 / 59$ & 0 & 0 & & $1-256$ & $1-4$ & $1-8$ & \\
\hline $11 / 25 / 59$ & $\mathbf{0}$ & 0 & 0 & $1-64$ & $1-8$ & & \\
\hline $1 / 11 / 60$ & $\mathbf{0}$ & 0 & 0 & 0 & $1-8$ & $1-64$ & \\
\hline $1 / 22 / 60$ & 0 & 0 & & & & & \\
\hline $4 / 27 / 60$ & $1-8$ & $1-32$ & & & & & + \\
\hline $5 / 4 / 60$ & & & 0 & $1-512$ & & & \\
\hline $7 / 21 / 60$ & & & & $1-256$ & & & \\
\hline
\end{tabular}

\section{SUMMARY}

Chronic pulmonary histoplasmosis and aspergillosis, chronic granulomatous type are symptomatically similar. 
Definitive diagnosis of pulmonary histoplasmosis should be made by the demonstration of the etiologic agent but in regard to aspergillosis, even if there is the presence of the Aspergillus in the sputum, definitive diagnosis is not easily made because the organisms are frequent laboratory contaminants.

$\mathrm{X}$-rays, serologic tests and skin tests are also important to aid the diagnosis of such diseases.

The treatment of both diseases appears to be ameable to definitive surgical therapy.

\section{REFERENCES}

1. Friedman, C. et al. : Dis. Chest, 30: 345, 1956.

2. Hughes, F. A. et al.: Ann. Surg., 144: 138, 1956.

3. Levy. E. S. et al.: A.M.A. Arch. Int. Med., 95: 118, 1955.

4. Pesle, G, D. et al.: Dis. Chest, $25: 172,1954$.

5. Rankin, N. E.: Brit. M. J. 1: 918, 1953.

6. Lehan, P. H. et al.: J. Chronic Dis., 5: 489, 1957.

7. Sutliff, W. D. et al.: Arch. Int. Med., 92: 571, 1953.

8. Tegiris, A. S. et al.: Ann. Int. Med., 48: 1414, 1958.

9. Pukett, T. F.: Am. J. Surg., $90: 92,1955$.

10. Furcolow, M. L. et al.: Am. Rev. Tuberc., 73: 609, 1956.

11. Furcolow, M. L.: Pub. Health Rep., 64: 1363, 1949.

12. Iwata, K. et al. : Nissin Igaku, 46: 294, 1959. (in Japanese)

13. Tamamura, T.: Nissin Igaku, 46:231, 1959. (in Japanese)

14. Iwata, K. et al. : Nihon Saikin Gaku Zassi, 13: 880, 1958. (in Japanese)

15. Tagami, N. et al.: Nihon Byori Gakkai Zassi, $47: 399,1968$. (in Japanese)

16. Wada, T.: Nissin Igaku, 45: 351, 1958. (in Japanese)

17. Hoshijima, K.: Nissin Igaku, 45: 353, 1958. (in Japanese) 